\title{
Rules and regulations for a pregnant endourologist: the European perspective
}

\author{
Patrick Juliebø-Jones ${ }^{1,2,4}$ (1) $\cdot$ Amelia Pietropaolo ${ }^{3,4} \cdot$ Anne-Francoise Spinoit ${ }^{3} \cdot$ Anne K. Bergesen ${ }^{1}$. \\ Gigja Guðbrandsdottir $^{1,2} \cdot$ Christian Beisland $^{1,2} \cdot$ Nicola von Ostau $^{5}$. Nina N. Harke Maria J. Ribal $^{6} \cdot$ Maria Zerva $^{7}$. \\ Ewa Bres-Niewada ${ }^{8} \cdot$ Patricia Zondervan $^{9} \cdot$ Liza McLornan $^{10}$. Stefania Ferretti ${ }^{11}$. Ursula Tonnhofer ${ }^{12}$. \\ Ulrike Hendrika Necknig ${ }^{13} \cdot$ Andreas Skolarikos $^{14} \cdot$ Bhaskar K. Somani $^{15}$
}

Received: 29 August 2021 / Accepted: 16 November 2021 / Published online: 7 December 2021

(c) The Author(s) 2021

\begin{abstract}
Introduction Working in surgery while pregnant is challenging. Navigating this period safely is of paramount importance. Anecdotal observation suggests that there exists great variation among European nations in regard to maternity leave and radiation safety.

The aim of this article was to gain insight into policy patterns and variations across Europe regarding these issues.

Methods A series of core question items was distributed to representatives across 12 nations Austria, Belgium, Germany, Greece, Iceland, Italy, Netherlands, Norway, Poland, Republic of Ireland, Spain and the United Kingdom).

Results The total number of weeks with full pay ranged from as little as 4 weeks in Belgium to 32 and Iceland. All countries included in this study give the option of additional weeks beyond the initial period, however at reduced pay. Some offer unpaid leave beyond this. Only 5/12 countries had a specific policy on when the pregnant surgeon should come off the oncall rota. Only Austria, Italy and Poland stipulate a requirement for the pregnant clinician to be replaced or be completely exempt in cases involving radiation. Only Germany, Iceland, Norway and Poland highlight the need to limit radiation dose in the first trimester. Beyond this, Germany alone provides written guidance for reduction in gown weight and along with Poland, display arguably the most forward-thinking approach to resting.

Conclusion There is a marked range in maternal leave policies across Europe. There also exists a lack of universal guidance on radiation safety for the pregnant urologist. There is urgent need for this void to be addressed.
\end{abstract}

Keywords Maternity leave $\cdot$ Radiation $\cdot$ Pregnancy $\cdot$ Endourology $\cdot$ Guideline

\section{Introduction}

A career in surgical specialties is widely recognized to cause difficulties in achieving a good work to life balance [1]. Pregnancy and caring for a newborn child present a further challenge to this equilibrium and it can be difficult to find harmony in navigating this life chapter. Furthermore, working through the course of pregnancy can be arduous both physically and mentally with concerns for the welfare of

Patrick Juliebø-Jones and Amelia Pietropaolo are joint first authors.

Patrick Juliebø-Jones

jonesurology@gmail.com

Extended author information available on the last page of the article the mother and the expected child. The recent findings from the United States (US) have revealed that residents take onaverage only 8 weeks of paid maternity leave [2]. Moreover, Altierio et al. determined that $42.5 \%$ take less than 2 weeks of leave [3]. This research also highlighted that many do not feel supported by fellow residents or their department when taking this time out. Additional obstacles in this regard includes a strain on the program of lack of universal policies. Consideration must also be given to risks for the unborn child and in the setting of urology this includes exposure to ionizing radiation during procedures. However, research by Macdonald et al. highlighted that guidelines regarding procedural safety policies are seldom [4]. Given that the projected workforce in urology is expected to result in more female urologists, this is a subject of great importance and relevance $[5,6]$. However, it remains under reported in world 
literature and anecdotal observation suggests that there exists great variation among European nations in regard to practice patterns and established policies.

The aim of this article was to explore this theme further and gain insight into policy patterns and variations across Europe regarding maternity leave and radiation safety.

\section{Methods and materials}

A series of core questions was delivered to one or more academic endourologists among various European nations affiliated to European Association of Urology (EAU) Young Academic Urology (YAU) groups and EAU section of UroTechnology (ESUT). This was a fact-based list of questions and not intended to include any subjective elements. One response was recorded from each of the included countries.

The majority of respondents had been through the process of parental leave either as resident and/or consultant and therefore having experience in this area. The questionnaire consisted of two parts: maternity leave and safety policies during pregnancy.

\section{Results}

Information was collected on 12 European countries (Austria, Belgium, Germany, Greece, Iceland, Italy, Netherlands, Norway, Poland, Republic of Ireland, Spain and the United Kingdom).

\section{Maternity leave}

There was considerable range in duration of standard maternity leave for urologists among these countries (14-26 weeks). Total number of weeks with full pay ranged from as little as 4 weeks in Belgium to a maximum of a possible 31 and 32 weeks in Norway and Iceland, respectively. All countries included in this study give the option of additional weeks beyond the initial period, however, the percentage of the previous salary that is paid varies hugely. For example, Poland offers additional leave, which can last up to 32 weeks at $60 \%$ of previous wage. In contrast, Greece allows for a further 24 weeks but this is completely unpaid. In certain countries, the mother is prohibited from returning to work after the birth for a fixed period (e.g. Germany-8 weeks).

Several countries offer the clinician to take a pause from their role for a period of time beyond these additional weeks. For example, in Spain and Poland, the mother has the ability to take 3 years of unpaid leave. In this regard, her previous role is protected and the work can be returned to afterwards. Most countries make additional allowances for special scenarios such as sole guardian of the child, multiple birth or if the child is born with a serious illness. Except from Spain where there is no set provision for leaving to commence maternity leave before the expected delivery date, every other country included in this study has a policy to allow pregnant urologists to take up maternity leave earlier. One of the most generous in this aspect is the UK and Norway where the individual can take leave from work 11 and 12 weeks before the due date, respectively. Only $5 / 12$ countries had a specific policy on when the pregnant surgeon should come off the on-call (emergency and out of hours) rota. One of the most flexible system appears to be in Italy, whereby the clinician can relinquish these duties at any time (optional and clinician may decide to continue). In Austria, the rules are stricter and clinicians must come off the on-call rota as soon as the pregnancy is announced to employer. In the other countries, it ranged from week 28 (Norway) to week 32 (Belgium). Further considerations are that in Italy, pregnant urologists do not work night shifts and during the Covid-19 pandemic, they do not have any patient contact during the pregnancy. In Germany, the clinician has the option to relinquish all night shift (or $24 \mathrm{~h}$ ) duties as soon as the pregnancy is announced. Her salary will remain as it was before.

Variations within a country do exist, for example in Belgium, depending on whether employment is in the private or public sector. For example, weeks with full pay is only 4 weeks in the private sector, but 8 weeks in the public sector (Table 1).

\section{Radiation safety and work environment}

With regard to the need to change duty if involved in cases involving radiation, Austria, Italy and Poland all stipulate a requirement for the pregnant clinician to be replaced or be completely exempt in these scenarios (Table 2). In contrast, the law in Greece and Belgium does not address this. In the remaining 7 countries, this is optional and observations from respondents were that in reality, the decision is determined locally between the individual and employer. Only Germany, Iceland, Norway and Poland highlight the need to limit radiation dose in the first trimester. Beyond this, Germany alone provides written guidance for reduction in gown weight and along with Poland, display arguably the most forward-thinking approach to resting. For example, the pregnant urologist cannot be in a continuous standing position (e.g. operating) for period of $2 \mathrm{~h}$ or more. In addition to this, Germany is the only nation to stipulate a limit on heavy lifting (max. $5 \mathrm{~kg}$ ). 


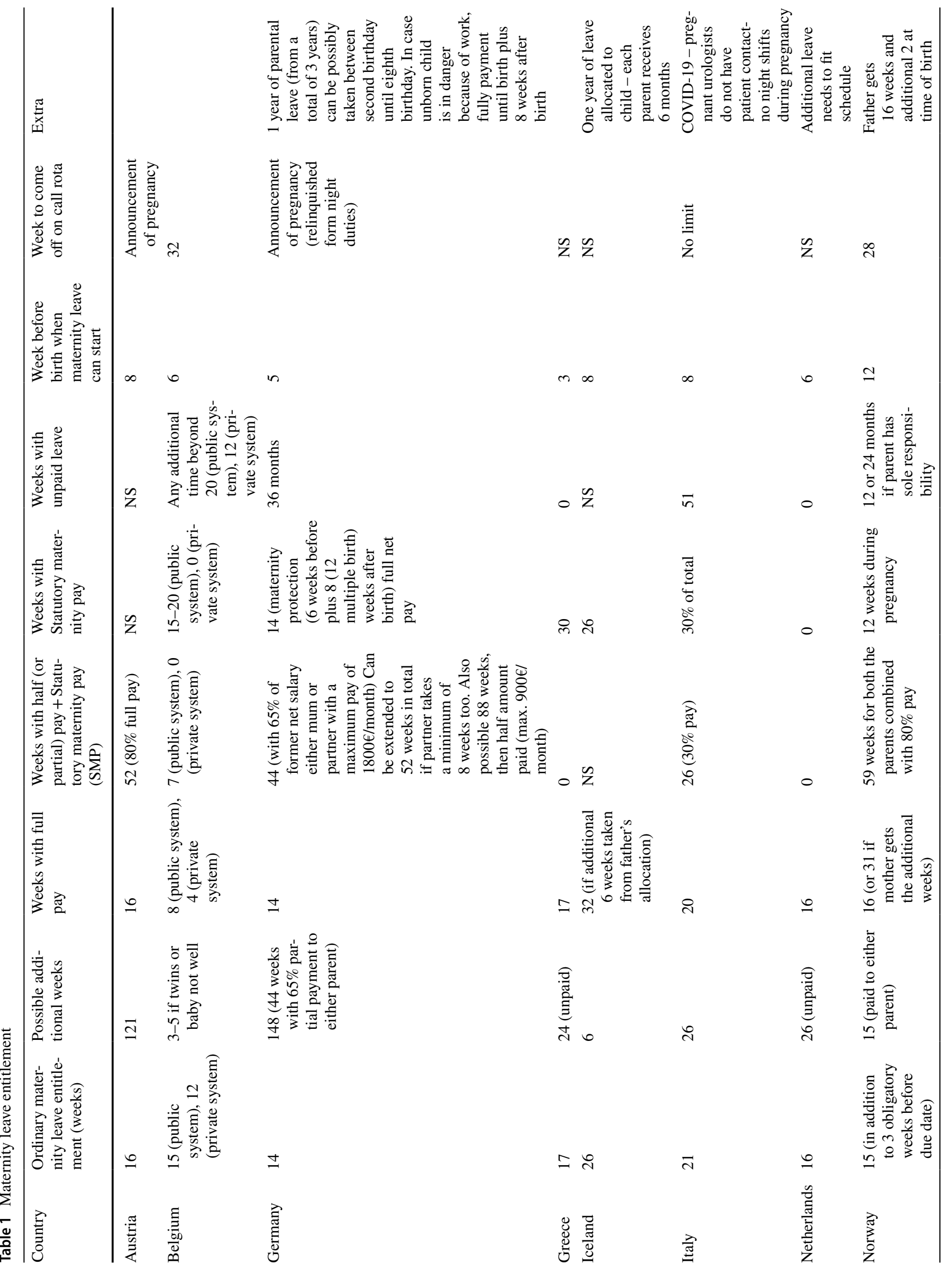




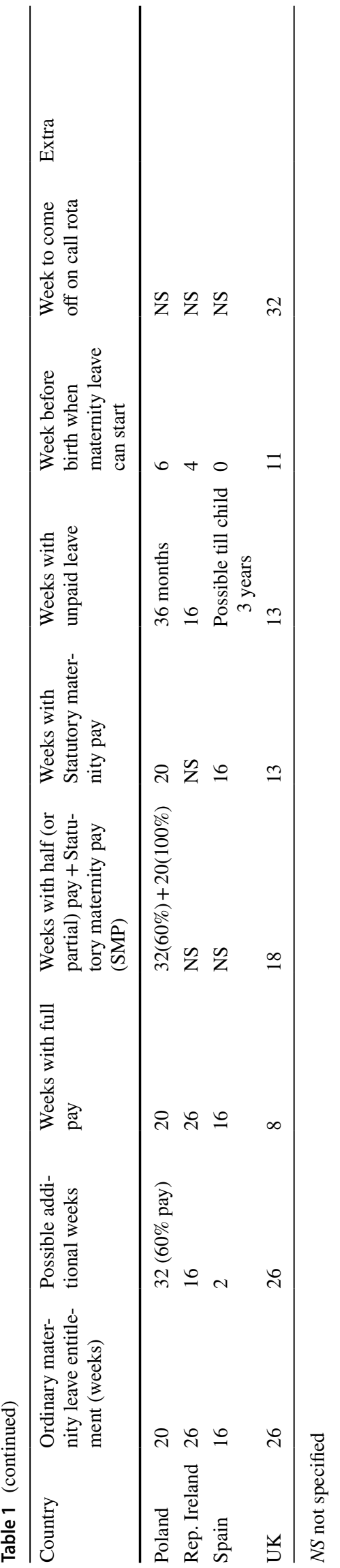

\section{Discussion}

\section{Key findings}

This study provides an overview of maternity leave rights and regulations among European countries. Based on the findings, it seems that as well as great variation, certain countries have more favorable maternity leave allowances with regard to time and financial renumeration. Germany and Poland appear to have the most detailed criteria surrounding radiation safety in the operating room. It is disappointing that many nations do not have clinician specific policies on many of these items including the Republic of Ireland which has none at all. It is therefore left to the individual and their local employer to devise and agree ad hoc plans for these worrying issues. However, a key reason for why there may not appear any obvious clinician specific regulation, e.g. Norway and Iceland, may be because it is covered within more generalized rules, which are embedded in higher order laws at a national level. The latter concern safety in the working environment and therefore radiation exposure for the general population.

\section{Risk factors for adverse pregnancy outcomes}

The importance of this topic cannot be understated. Stress in pregnancy is a known risk factor for adverse outcomes for both mother and unborn child and heavy workload can result in reduced birth weight $[7,8]$. Working in an excess of $32 \mathrm{~h}$ a week has also been shown to increase the risk of intrauterine growth restriction (IUGR) and reduced birth weight as a result [9]. Fatigue is associated with an increased risk of miscarriage [10]. The European Union (EU) has released a list of possible risks that a pregnant worker can encounter during her daily work [11]. Incorporation of such guidance into user friendly and universal regulations is therefore paramount to support healthy pregnancies.

\section{Maternity pay}

Provision of suitably paid maternity leave support is essential. Aitken et al. conducted a systematic review comparing paid maternity leave versus nonpaid maternity leave [12]. The former provided better maternal and infant health benefits. Stearns et al. demonstrated that since 1978, when paid leave was introduced in the US, the rate of low birth weight and early term birth decreased by 3.2 and $6.6 \%$ respectively [13]. In a similar manner, Jou et al., determined that paid maternity leave reduced the odds of maternal and infant rehospitalization in US [7]. Based on these findings, regulation has changed worldwide and the median number of weeks of 
World Journal of Urology (2022) 40:857-864

861

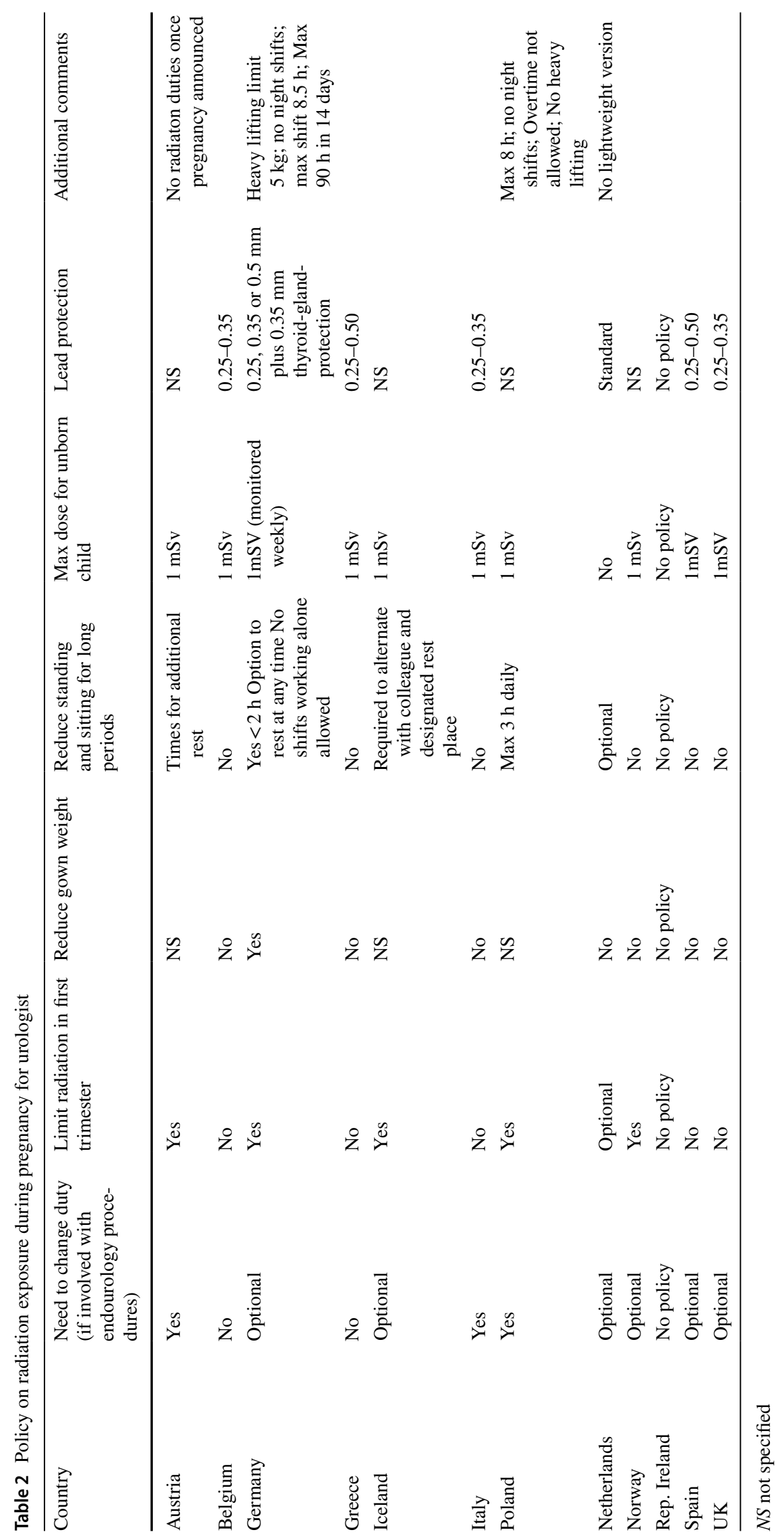

Springer 
paid leave for mothers among Organisation for Economic Cooperation and Development countries, had risen from 14 weeks in 1980 to 42 weeks by 2011 [14].

\section{Gender variations in workforce}

The topic is a matter of heated debate lately as the number of women enrolled in medical school and specialty training programs has increased dramatically over the past several decades [5]. This new wave has led the way for a renewed interest towards parental leave and working mothers needs in the medical field. In 2015, the UK government introduced new flexible leave allowances that encouraged and facilitated for working parents to share leave after the birth or adoption of their child. This allowed both parents in turn, to spend time with their newborn child up to a maximum of 50 weeks' leave and 39 weeks' statutory shared parental pay, shared between parents in the first year after birth or adoption. Indeed, other nations now implement a more joint approach. As of 2021, mothers and fathers in Iceland are both allocated 6 months equally. The philosophy behind this approach, which is also shared by other Scandinavian countries appears to be centred around this period of leave belonging to the newborn child and then divided among the parents thereafter. It also highlights the caution needed when interpreting information regarding maternity leave. What appears to be less time in one country may in fact be as a result of that country allocating more time to the other parent.

\section{Radiation}

Radiation protection in pregnancy is based on the knowledge that exposure to $1 \mathrm{mSv}$ increases the risk of congenital malformation by $0.008 \%$, it is, therefore, recommended by International Commission of Radiological Protection (IRCP) that pregnant workers should not be exposed to more than $1 \mathrm{mSv}$ [15]. A standard $0.5 \mathrm{~mm}$ lead apron can block up to $99 \%$ of radiation and maternal tissues block a further $70 \%$ [16]. Uzoigwe et al. concluded that up to 800 orthopaedic procedures can be safely performed before the pregnancy radiation exposure limit is exceeded [17]. However, the latter will vary depending on type of surgery performed. A similar conclusion was drawn by Birnie for radiation exposure among urologists [18]. Comparison between urologist exposure during fluoroscopy and the normal population exposed to environmental radiation, did not show any relevant difference in radiations recorded. Unfortunately, clear and standardised guidance during pregnancy is not always available and often surgeons have to rely on good-will rather than a formal hospital policy. Many pregnant workers are forced to find their own methods to mitigate risk such as by wearing double led gown protection or a lighter $0.25 \mathrm{~mm}$ body gown plus a skirt so there is overlap at the abdomen but less weight on the shoulders. Standing two metres away from the image intensifier will also reduce exposure by a factor of four. This can allow the surgeon to safely be in theatre while supervising a junior doctor.

\section{Further considerations}

The perspective on this topic may differ between resident and consultant. For example, the latter may feel more established in their role and more comfortable in highlighting their rights. Although time lost away from training appears to be honored once leave has come to an end, it can be challenging and stressful to spend time away from a craft-based profession, such as surgery. A mother may even therefore prefer the option to share the leave more equally with the father.

Although most countries offer options to for example change duty when performing fluoroscopy, it is arguable that this should be mandatory, which could remove the stress or burden to the pregnant urologist who has to decide this for themselves.

\section{What is lacking?}

As our study confirmed, in many countries the radiation protection policy is clear in regard to maximum radiation exposure. However, the majority have no fixed rule established for lead gown usage, exposure risk during the first trimester and change of duty in case of heavy workload or fluoroscopy usage. Although in some countries such policy is available, often it is only optional and difficult to find, which leaves the female surgeon to feel poorly supported and in a vulnerable position where they feel the obligation to decide for themselves how best to proceed and tackle this taboo subject.

\section{Limitations}

To our knowledge, this is one of the first studies to address the variation in maternity leave and safety regulations for urologists across Europe. Several limitations do exist including that many other European and non-European countries were not represented.

However, we do believe the number collected is sufficient to highlight the diversity in this area and the need for action. Full comparison on all the items included is not possible as many countries appeared to not specify and even have no policy on these matters. 


\section{Recommendations}

Development of universal guidance on for example radiation safety in pregnancy by international bodies such as the European Association of Urology (EAU) would be a valuable first step in improving the conditions for pregnant urologists and their wellbeing. These should be easily available and would serve as a blueprint for adoption by the relevant societies of individual nations. While a specific policy for the pregnant urologist may not exist, it may be that is in encompassed by a law on a national level and therefore there does exist protection for the clinician and guidance for the employer accordingly. However, it is our feeling that international and national bodies in urology should address this topic and disseminate transparent guidance to remove uncertainty and worry.

\section{Conclusion}

This study highlights the range of maternal leave policies among European nations and the lack of universal guidance on radiation safety for the pregnant urologist. There is urgent need for this void to be addressed to better support the pregnant urologist and ensure the well-being of them and their unborn child.

Author contributions J-JP, PA, SAF, BAK, GG,BC, ON, HNN, RM, ZM, B-NE, ZP, ML, FS, TU, NUH, SA, SBK: protocol/project development, data collection or management, data analysis, manuscript writing/editing.

Funding Open access funding provided by University of Bergen (incl Haukeland University Hospital). None.

\section{Declarations}

Conflict of interest None to be declared by any of the authors.

Research involving human participants and/or animals Not applicable.

Informed consent Not applicable.

Open Access This article is licensed under a Creative Commons Attribution 4.0 International License, which permits use, sharing, adaptation, distribution and reproduction in any medium or format, as long as you give appropriate credit to the original author(s) and the source, provide a link to the Creative Commons licence, and indicate if changes were made. The images or other third party material in this article are included in the article's Creative Commons licence, unless indicated otherwise in a credit line to the material. If material is not included in the article's Creative Commons licence and your intended use is not permitted by statutory regulation or exceeds the permitted use, you will need to obtain permission directly from the copyright holder. To view a copy of this licence, visit http://creativecommons.org/licenses/by/4.0/.

\section{References}

1. Rich A, Viney R, Needleman S, Griffin A, Woolf K (2016) "You can't be a person and a doctor": the work-life balance of doctors in training-a qualitative study. BMJ Open 6(12):e013897. https://doi.org/10.1136/bmjopen-2016-013897 (PMID: 27913563; PMCID: PMC5168633)

2. Juengst SB, Royston A, Huang I, Wright B (2019) Family leave and return-to-work experiences of physician mothers. JAMA Netw Open 2(10):e1913054. https://doi.org/10.1001/jaman etworkopen.2019.13054

3. Altieri MS, Salles A, Bevilacqua LA et al (2019) Perceptions of surgery residents about parental leave during training. JAMA Surg 154(10):952-958. https://doi.org/10.1001/jamasurg.2019.2985

4. MacDonald SM, Raman JD (2021) Widely variable parental leave practices for urology residency programs in the United States. Urology. https://doi.org/10.1016/j.urology.2020.12.049 (Epub ahead of print; PMID: 33587938)

5. Nam CS, Daignault-Newton S, Herrel LA, Kraft KH (2020) The future is female: urology workforce projection From 2020 to 2060. Urology. https://doi.org/10.1016/j.urology.2020.08.043 (Epub ahead of print; PMID: 32890624)

6. Holton MR, Bailey K (2021) Women in urology. Urol Clin North Am 48(2):187-194. https://doi.org/10.1016/j.ucl.2020.12.003 (Epub 10 Mar 2021; PMID: 33795052)

7. Jou J, Kozhimannil KB, Abraham JM, Blewett LA, McGovern PM (2018) Paid maternity leave in the United States: associations with maternal and infant health. Matern Child Health J 22(2):216-225. https://doi.org/10.1007/s10995-017-2393-x (PMID: 29098488)

8. Loomans EM, van Dijk AE, Vrijkotte TG, van Eijsden M, Stronks K, Gemke RJ, Van den Bergh BR (2013) Psychosocial stress during pregnancy is related to adverse birth outcomes: results from a large multi-ethnic community-based birth cohort. Eur J Public Health 23(3):485-491. https://doi.org/10.1093/eurpub/cks097 (Epub 31 Jul 2012; PMID: 22850187)

9. Dunkel Schetter C, Tanner L (2012) Anxiety, depression and stress in pregnancy: implications for mothers, children, research, and practice. Curr Opin Psychiatry 25(2):141-148. https://doi.org/ 10.1097/YCO.0b013e3283503680 (PMID: 22262028; PMCID: PMC4447112)

10. Qu F, Wu Y, Zhu YH, Barry J, Ding T, Baio G, Muscat R, Todd BK, Wang FF, Hardiman PJ (2017) The association between psychological stress and miscarriage: a systematic review and metaanalysis. Sci Rep 7(1):1731. https://doi.org/10.1038/s41598-01701792-3 (PMID: 28496110; PMCID: PMC5431920)

11. European Economic Commission.Communication from the Commission on the guidelines on the assessment of the chemical, physical and biological agents and industrial processes considered hazardous for the safety or health of pregnant workers and workers who have recently given birth or are breastfeeding (Council Directive 92/85/EEC)/*C0M/2000/0466 final

12. Aitken Z, Garrett CC, Hewitt B, Keogh L, Hocking JS, Kavanagh AM (2015) The maternal health outcomes of paid maternity leave: a systematic review. Soc Sci Med 130:32-41. https://doi.org/ 10.1016/j.socscimed.2015.02.001 (Epub 4 Feb 2015; PMID: 25680101)

13. Stearns J (2015) The effects of paid maternity leave: evidence from temporary disability insurance. J Health Econ 43:85-102. https://doi.org/10.1016/j.jhealeco.2015.04.005 (Epub 7 May 2015; PMID: 26218984)

14. Council Directive 92/85/EEC of 19 October 1992 on the introduction of measures to encourage improvements in the safety and health at work of pregnant workers and workers who have recently given birth or are breastfeeding (tenth individual Directive within the meaning of Article 16 (1) of Directive 89/391/EEC) 
15. International Commission on Radiological Protection (2000) Pregnancy and medical radiation. Ann ICRP 30(1):1-43

16. International Commission for Radiological Protectio (2000) ICRP Publication 117. Radiological protection in fluoroscopically guided procedures outside the imaging department. Ann ICRP 40(6): $1-102$

17. Uzoigwe CE, Middleton RG (2012) Occupational radiation exposure and pregnancy in orthopaedics. J Bone Joint Surg Br 94(1):23-27
18. Birnie AM, Keoghane SR (2015) Radiation exposure to a pregnant urological surgeon—what is safe? BJU Int 115(5):683-685

Publisher's Note Springer Nature remains neutral with regard to jurisdictional claims in published maps and institutional affiliations.

\section{Authors and Affiliations}

Patrick Juliebø-Jones ${ }^{1,2,4}$ (1) Amelia Pietropaolo ${ }^{3,4} \cdot$ Anne-Francoise Spinoit ${ }^{3} \cdot$ Anne K. Bergesen $^{1}$. Gigja Guðbrandsdottir ${ }^{1,2}$. Christian Beisland ${ }^{1,2}$. Nicola von Ostau ${ }^{5}$. Nina N. Harke ${ }^{5}$ Maria J. Ribal ${ }^{6} \cdot$ Maria Zerva $^{7}$. Ewa Bres-Niewada ${ }^{8}$. Patricia Zondervan ${ }^{9} \cdot$ Liza McLornan $^{10}$. Stefania Ferretti ${ }^{11}$. Ursula Tonnhofer ${ }^{12}$. Ulrike Hendrika Necknig ${ }^{13} \cdot$ Andreas Skolarikos $^{14} \cdot$ Bhaskar K. Somani $^{15}$

1 Department of Urology, Haukeland University Hospital, Bergen, Norway

2 Department of Clinical Medicine, University of Bergen, Bergen, Norway

3 Department of Urology, Ghent University Hospital, Ghent, Belgium

4 Young Academic Urologists (YAU), Urolithiasis \& Endourology Working Party, Arnhem, The Netherlands

5 Department of Urology, Universitätsklinikum Essen, Essen, Germany

6 Department of Urology, Hospital Clinic, University of Barcelona, Barcelona, Spain

7 Department of Urology, Red Cross Hospital, Athens, Greece

8 Department of Urology, Roefler Memorial Hospital, Pruszkow, Poland
9 Department of Urology, Amsterdam Medical Centers, Amsterdam, The Netherlands

10 Department of Urology, Beaumont and Connolly Hospitals, Dublin, Republic of Ireland

11 Department of Urology, University Hospital of Parma, Parma, Italy

12 Department of Paediatric Surgery, Medical University of Vienna, Vienna, Austria

13 Department of Urology, Klinikum Garmisch-Partenkirchen, Garmisch-Partenkirchen, Germany

14 Department of Urology, National and Kapodistrian University of Athens, Athens, Greece

15 Department of Urology, University Hospital Southampton, Southampton, UK 